\title{
Maternal overweight but not paternal overweight before pregnancy is associated with shorter newborn telomere length: evidence from Guangxi Zhuang birth cohort in China
}

Bincai Wei', Yantao Shao ${ }^{2}$, Jun Liang ${ }^{1}$, Peng Tang ${ }^{1}$, Meile Mo ${ }^{1}$, Bihu Liu', Huishen Huang ${ }^{1}$, Hui Juan Jennifer Tan ${ }^{3}$, Dongping Huang ${ }^{4^{*}}$, Shun Liu $^{5^{*}}$ and Xiaogiang Qiu ${ }^{1^{*}}$ (D)

\begin{abstract}
Background: Telomere length (TL) is variable at birth and is inversely associated with body mass index (BMI) in adulthood. A growing number of evidences suggested that a higher maternal pre-pregnancy BMI results in adverse offspring health outcomes, especially shorter newborn TL. However, a newborn's genetic endowment is equally derived from both parents, the association between parental pre-pregnancy BMI and newborn TL has been rarely discussed. We aimed to determine the association between parental pre-pregnancy BMI and newborn TL.

Methods: A total of 1082 parent-newborn pairs were recruited from the Guangxi Zhuang Birth Cohort (GZBC). TL in cord blood was measured using quantitative real-time polymerase chain reaction (qPCR) and expressed as the ratio of telomere copy number to single-copy gene number (T/S). A series of linear regressions were performed to assess the associations between parental pre-pregnancy BMl and newborn TL.

Results: Mothers who were overweight before pregnancy had significantly shorter cord blood telomere length in their newborns than those who were normal weight before pregnancy [percentage change: $-7.96 \%$ (95\% Cl: 14.49 to $-0.69 \% ; P=0.032)$ ]. Further analysis of the combined effects of parental weight status on newborn TL showed that TL was significantly shortened among newborns whose mothers were overweight and fathers were of healthy weight when compared with those whose mothers and fathers were both of normal weight [percentage (Continued on next page)
\end{abstract}

\footnotetext{
*Correspondence: dongpinghuang@gxmu.edu.cn; liushun@gxmu.edu.cn; xqqiu9999@163.com

${ }^{4}$ Department of Sanitary Chemistry, School of Public Health, Guangxi Medical University, No. 22 Shuangyong Road, Nanning 530021, Guangxi, China ${ }^{5}$ Department of Maternal, Child and Adolescent Health, School of Public Health, Guangxi Medical University, No. 22 Shuangyong Road, Nanning 530021, Guangxi, China

'Department of Epidemiology and Health Statistics, School of Public Health,

Guangxi Medical University, No. 22 Shuangyong Road, Nanning 530021, Guangxi, China

Full list of author information is available at the end of the article
}

(c) The Author(s). 2021 Open Access This article is licensed under a Creative Commons Attribution 4.0 International License, which permits use, sharing, adaptation, distribution and reproduction in any medium or format, as long as you give appropriate credit to the original author(s) and the source, provide a link to the Creative Commons licence, and indicate if changes were made. The images or other third party material in this article are included in the article's Creative Commons licence, unless indicated otherwise in a credit line to the material. If material is not included in the article's Creative Commons licence and your intended use is not permitted by statutory regulation or exceeds the permitted use, you will need to obtain permission directly from the copyright holder. To view a copy of this licence, visit http://creativecommons.org/licenses/by/4.0/ The Creative Commons Public Domain Dedication waiver (http://creativecommons.org/publicdomain/zero/1.0/) applies to the data made available in this article, unless otherwise stated in a credit line to the data. 
(Continued from previous page)

change: $-8.38 \%(95 \% \mathrm{Cl}$ : 15.47 to $-0.92 \% ; P=0.028)$ ]. Subgroup analysis indicated these effects were more

pronounced among male newborns and those whose paternal age $<31$ years or maternal age $\geq 28$ years at delivery.

Conclusions: Maternal pre-pregnancy overweight, but not paternal pre-pregnancy overweight is associated with shorter newborn TL. Weight control in reproductive women and effective healthy weight management before pregnancy may be of particular benefit for improving longevity and life quality of offspring.

Keywords: Parents, Pre-pregnancy body mass index, Telomere length, Cord blood, Newborns

\section{Background}

The phenomenon of overweight and obesity has been a heated topic in the past decades, which is a major public health problem of most countries in the world, including China. With the concept of "Giving better birth and care" spreading in China, overweight and obesity before pregnancy has gradually attracted more attention. Previous studies had reported that higher parental prepregnancy BMIs were associated with adverse offspring outcomes, such as higher risk of macrosomia [1], adverse body composition after birth [2], type 1 diabetes [3], higher blood pressure [4] and so on.

The telomere is a terminal section of a chromosome, which contains a number of repeats of the sequence TTAGGG, and it is responsible for maintaining chromosome integrity and genome stability [5]. Naturally, the telomeres are gradually shortened when a cell undergoes DNA replication and cell division. For this reason, scientists believe that telomere length (TL) is not only a biomarker of biological aging, but also a "telomeric clock" [6] and a prediction of life span [7, 8]. TL has been shown to be associated with several age-related diseases, such as type 2 diabetes [9], cardiovascular disease [10] and cancer [11]. Considering the importance of telomeres, clarifying the related factors of TL is of great significance for maintaining the normal function of telomeres.

A previous study showed that TL is hereditary and largely determined before adulthood, and early life environmental factors are the main determinants of TL throughout the course of human life [12]. The early life determinants are mainly from maternal factors, such as maternal stress [13], maternal menarche age [14], maternal second-hand smoke exposure [15], and environment risk such as cadmium exposure [16]. In relation to prepregnancy overweight and obesity, the effect of maternal BMI on the TL of the offspring has been well characterized [17]. However, the genetic endowment of a newborn is equally derived from both parents. It remains unclear whether paternal pre-pregnancy overweight and obesity has an effect on newborn TL, and whether parental pre-pregnancy weight status has interactive effects on newborn TL. In the present study, we aimed to investigate the association of parental pre-pregnancy BMI with newborn TL.

\section{Methods}

\section{Study population and data collection}

Guangxi is the ninth largest province with over 49.2 million residents in southwestern China, however, the per capita Gross regional product (GRP) of Guangxi was only ranked 26th to 28th among China's 31 provinces from 2003 to 2017 [18]. Data between June 2015 and May 2018 for this study were extracted from the Guangxi Zhuang Birth Cohort (GZBC), which was conducted in 6 county-level hospitals with visitors mainly from rural areas, and details on the ongoing GZBC have been introduced in our previous study [19]. In the present study, a total of 1239 mothers were extracted out for TL detection. However, 157 participants were excluded due to twins $(n=15)$ and stillbirth $(n=9)$, missing information on parental BMI $(n=38)$, unavailable cord blood DNA sample for TL measurement $(n=69)$, and large variabilities TL measurements between duplicate measurements for cord blood telomere $(n=26)$ (Flowchart was presented in Additional file 1). A total of 1082 parent-newborn pairs (singletons) with full data and cord blood telomere were included for the final analyses. This study protocol was approved by the ethical committee of Guangxi Medical University (No.20140305-001). Written informed consent was obtained from all participants.

On the first antenatal visit, the personal information was collected at the hospitals by professionally trained interviewers through a standardized and structured questionnaire. Information on maternal factors around pregnancy and newborns was obtained from medical data. Gestational age (weeks) was estimated based on ultrasound data or the date of last menstrual period selfreported by the pregnant women. Pre-pregnancy weight and height measured on the first antenatal visit was selfreported by mothers and fathers, respectively. BMI was calculated as weight $/$ height $^{2}\left(\mathrm{~kg} / \mathrm{m}^{2}\right)$. The categories of parental BMIs were based on the BMI cut-offs for Chinese adults recommended by the Working Group of Obesity in China [20]. BMI $<18.5 \mathrm{~kg} / \mathrm{m}^{2}, 18.5 \leq \mathrm{BMI}<$ 
$24.0 \mathrm{~kg} / \mathrm{m}^{2}, 24.0 \geq \mathrm{BMI}<28.0 \mathrm{~kg} / \mathrm{m}^{2}$, and BMI $\geq 28.0 \mathrm{~kg} /$ $\mathrm{m}^{2}$, was defined as underweight, normal weight, overweight and obesity, respectively.

\section{Cord blood collection and relative telomere length measurement}

Cord blood was drawn into $5 \mathrm{~mL}$ EDTA tubes immediately after delivery. Samples were centrifuged at 4000 rpm for $10 \mathrm{~min}$ and blood tubes were stored at $-80^{\circ} \mathrm{C}$. Genomic DNA extraction kit (Aidlab Biotechnologies) was used to extract DNA from leukocytes of umbilical cord blood according to the manufacturer's instructions. DNA samples with the A260/A280 ratio within the range 1.8 to 2.0 were considered eligible. A real-time quantitative polymerase chain reaction (qPCR) method described by Cawthon [21] was used to examined the relative TL in each DNA sample. Relative TL was determined as the ratio of telomere repeat copy number $(\mathrm{T})$ to a single copy gene (36B4) copy number (S). The primers sequences of telomeric gene and single-copy gene (36B4) were as follows. Forward primer of telomeric gene: 5 '-CGGTTTGTTTGGGTTTGGGTTTGG GTTTGGGTTTGGGTT-3'; reverse primer of telomeric gene: $\quad 5^{\prime}$-GGCTTGCCTTACCCTTACCCTTACCC TTACCCTTACCCT-3'; forward primer of 36B4: 5' CAGCAAGTGGGAAGGTGTAATCC-3'; reverse primer of 36B4: 5'-CCCATTCTATCATCAACGGGTA CAA- $3^{\prime}$. For both telomeric gene and single copy gene (36B4), reaction mixture $(20 \mu \mathrm{L})$ contained $1 \mu \mathrm{L}$ of genomic DNA (10 ng/ $\mu \mathrm{L}), 10 \mu \mathrm{L}$ of PowerUp SYBR Green Master Mix (2X), $100 \mathrm{nM}$ of the forward, and $100 \mathrm{nM}$ of the reverse; RNase free water was added to the final volume. For the telomere PCR reactions, the cycling conditions were $2 \mathrm{~min}$ at $50^{\circ} \mathrm{C}, 2 \mathrm{~min}$ at $95^{\circ} \mathrm{C}$, followed by 40 cycles of $95^{\circ} \mathrm{C}$ for $15 \mathrm{~s}$, then $62^{\circ} \mathrm{C}$ for $1 \mathrm{~min}$. For the 36B4 PCR reactions, the cycling conditions were $2 \mathrm{~min}$ at $50{ }^{\circ} \mathrm{C}, 2 \mathrm{~min}$ at $95^{\circ} \mathrm{C}$, followed by 40 cycles of $95^{\circ} \mathrm{C}$ for $15 \mathrm{~s}, 62^{\circ} \mathrm{C}$ for $20 \mathrm{~s}$, and $72^{\circ} \mathrm{C}$ for $1 \mathrm{~min}$. Each sample was measured in duplicates for both $\mathrm{T}$ and $\mathrm{S}$, and was performed in separate 96-well plates using a StepOnePlus real-time PCR system (Applied Biosystems). A standard reference genomic DNA sample was randomly selected from all quality samples. The standard curve, plotted using the standard reference genomic DNA sample, was utilized by two-fold serially dilution of one reference DNA sample to generate a 7-point curve with DNA concentration ranging from 3.125 to $200 \mathrm{ng} / \mu \mathrm{L}$ $\left(R^{2} \geq 0.98\right)$. Replicates of each plate were done to ensure reliable values. The qPCR amplification efficiency values were $98 \%$ for $\mathrm{T}$ and $101 \%$ for $\mathrm{S}$. The coefficient variations within the duplicates were $0.47 \%$ for the telomere runs and $0.61 \%$ for the single copy runs. A positive standard reference genomic DNA sample and a negative standard reference genomic DNA sample in each 96- well plate was set to calculate the $\Delta \mathrm{Ct}$ for each tested sample. The $2^{-\Delta \Delta C t}$ method was used to calculate the average relative TL [22].

\section{Statistical analysis}

Mean (SD) was used to describe the normally distributed continuous variables, median (interquartile range, IQR) for skewed data, and the numbers (percentages) was used to describe the categorical variables. The relative cord blood TL showed skewed distribution and were Log10 transformed to improve normal distribution. To study potential confounding structure in our dataset, we used ANOVA and Chi-square test to assess the distributions of continuous variables and categorical variables across the 3 categories of maternal pre-pregnancy BMI (underweight, normal weight, and overweight), respectively. Due to the small number of underweight fathers $(1.75 \%)$, we combined underweight and normal weight parents to make up the group of healthy weight (BMI < $24.0 \mathrm{~kg} / \mathrm{m}^{2}$ ) parents in the analysis of the impact of paternal BMI and the combined effects of parental weight status on newborn TL.

Pearson correlation and restricted cubic spline analysis was used to detect the linear and non-linear relationship between parental BMIs and newborns TL, respectively. Multiple linear regression models were also conducted to examine the association between parental BMI categories and newborn TL. We selected covariates based on prior knowledge, which included parental demographic characteristics (parental age at delivery, weight and height), and maternal lifestyles (drinking and smoking before pregnancy, passive smoking during pregnancy). Maternal factors around pregnancy, included residential place, parity, gravidity, pregnancy comorbidities or complications (diabetes, hypertension, preeclampsia, hyper- or hypothyroidism, digestive system diseases and blood system diseases), and cesarean section. Newborns' factors, included sex, gestational age, and anthropometric measures. In model $\mathrm{A}$, we adjusted for parental age at delivery and newborns' factors. In model B, we additionally adjusted for maternal factors around pregnancy. Since only two mothers smoked before pregnancy, the factor of smoking before pregnancy was not included in the adjusted models. As previous studies showed effects of paternal age and newborn sex on newborn TL $[6,17]$, we also performed subgroup analysis stratified by newborn sex, the median age of mothers ( 28 years) and fathers ( 31 years). To evaluate the robustness of our study, we performed sensitivity analyses that excluded mothers who drank before pregnancy, those who underwent passive smoking during pregnancy, those who experienced pregnancy comorbidities or complications, and newborns with preterm birth or low birth weight. Considering that air pollution has 
an important impact on TL [23, 24], we also excluded participants from urban areas. The relationship between parental BMI and newborn TL was expressed as a regression coefficient ( $\beta$ value) and corresponding 95\% confidence interval $(\mathrm{CI})$. To express the relative change in newborn TL in each model, we calculated the percentage change as follow: percentage change $=\left(10^{\beta}-1\right) \times$ $100 \%$. The SPSS software version 25.0 and $R$ version 4.0.2 were used to carry out all statistical tests, and $P$ value $<0.05$ was considered as statistically significant.

\section{Results}

\section{Study participants}

All in all, the mean ages of mothers and fathers at delivery were 28.5 years and 31.4 years, respectively. The mean pre-pregnancy BMIs of mothers and fathers were $20.2(2.3) \mathrm{kg} / \mathrm{m}^{2}$ and $22.1(1.4) \mathrm{kg} / \mathrm{m}^{2}$, respectively. The number of overweight participants was 74 (6.8\%) and 87 $(8.0 \%)$ for mothers and fathers, respectively. Additionally, there were no obese parents and only 2 mothers smoked before pregnancy, and 1013 (93.6\%) mothers from rural areas. The mean birth weight of newborns was 3120.3 (384.0) g. Among 1082 newborns, 582 were male, accounting for $53.8 \%$. The gestational age of the newborns was from 34 to 42 weeks, and the average gestational age was 38.66 (1.24) weeks, and 40 of them were preterm birth (gestational age $<37$ weeks). Higher maternal pre-pregnancy BMI was significantly associated with increased newborn birth weight, maternal age and paternal age (all $P<0.001)$. The median (IQR) of newborns' relative cord blood TL was $1.058(0.877,1.265)$. The baseline characteristics of participants according to maternal pre-pregnancy BMI categories are showed in Table 1.

\section{Association between parental pre-pregnancy BMI and newborn TL}

As there was no significant relationship found between parental BMI and newborn TL after conducting the Pearson correlation and restricted cubic spline analysis (Additional files 2 and 3), we used the multivariate linear regression model to test the associations by transforming parental BMI into categorical variables. As shown in Table 2, the newborn TL of overweight mothers were significantly shortened by $8.17 \%(95 \% \mathrm{CI},-14.89$ to $0.92 \% ; P=0.026)$ after adjusting for parental age at delivery and newborn factors (newborn sex, gestational age and birth weight) when compared to normal weight mothers. Even after additionally adjusting for maternal factors (residential place, gravidity, parity, drinking before pregnancy, passive smoking during pregnancy, pregnancy comorbidities or complications, and cesarean section), a significant difference [percentage change: $-7.96 \%$ (95\%CI, -14.49 to $-0.69 \% ; P=0.032$ )] was still observed. However, there was no significant effect found of paternal BMI on newborn relative TL in cord blood. Further analysis of the combined effect of parental BMI on newborn TL showed that TL was significantly shortened by $8.38(95 \% \mathrm{CI},-15.47$ to $-0.92 \% ; P=0.028)$ among the newborns with overweight mothers and fathers of healthy weight when compared with those whose mothers and fathers were both of normal weight in the fully adjusted model. In addition, we had considered paternal lifestyle factors into the analysis between parental pre-pregnancy BMI and newborn TL, however, there was a lot of missing data $(n=437)$ about paternal lifestyle factors (drinking and smoking before pregnancy) and there was still a trend that maternal pre-pregnancy overweight was inversely associated with newborn TL, although no statistical significance (Additional file 4).

\section{Stratified analysis by newborn sex and parental age}

We further conducted stratified analysis by newborn sex and parental age. We found that the association between overweight mothers and newborn TL was more pronounced among male newborns (Table 3). Even after additional adjusting for maternal factors, a trend still existed between overweight mothers and shortened newborn TL [percentage change: $-9.01 \%$ (95\%CI: -17.40 to $0.23 \% ; P=0.054)]$. We found a trend that the combined effect of parental weight status on newborn TL tend to be more obvious among male newborns in the fully adjusted model [percentage change: $-8.80 \%$ (95\%CI: 17.59 to $0.69 \% ; P=0.068)]$. However, we found no significant effect of paternal BMI on newborn TL in cord blood. When stratifying by parental age, we found single effects of maternal BMI and the combined effect of parental BMI on newborn TL were more pronounced among those whose paternal age $<31$ years or those whose maternal age $\geq 28$ years (Tables 4 and 5 , respectively). However, no significant interactions were found between parental pre-pregnancy BMI and newborn sex or parental age (all $P$ for interaction $>0.10$ ) on the changes of newborn TL (Additional file 5).

\section{Sensitivity analyses}

Sensitivity analyses indicated that the results were essentially unchanged after excluding data of mothers who drank before pregnancy, exposed to passive smoking during pregnancy, had pregnancy comorbidities or complications, gave birth to premature or low birth weight newborns, and participants from urban areas (Table 6).

\section{Discussion}

In the present study, we investigated the association of parental pre-pregnancy BMI with newborn TL by using data from the GZBC. We found that mothers who were overweight before pregnancy had significantly shorter cord blood telomere length in their newborns than those 
Table 1 Characteristics of parent-newborn pairs according to maternal pre-pregnancy BMI

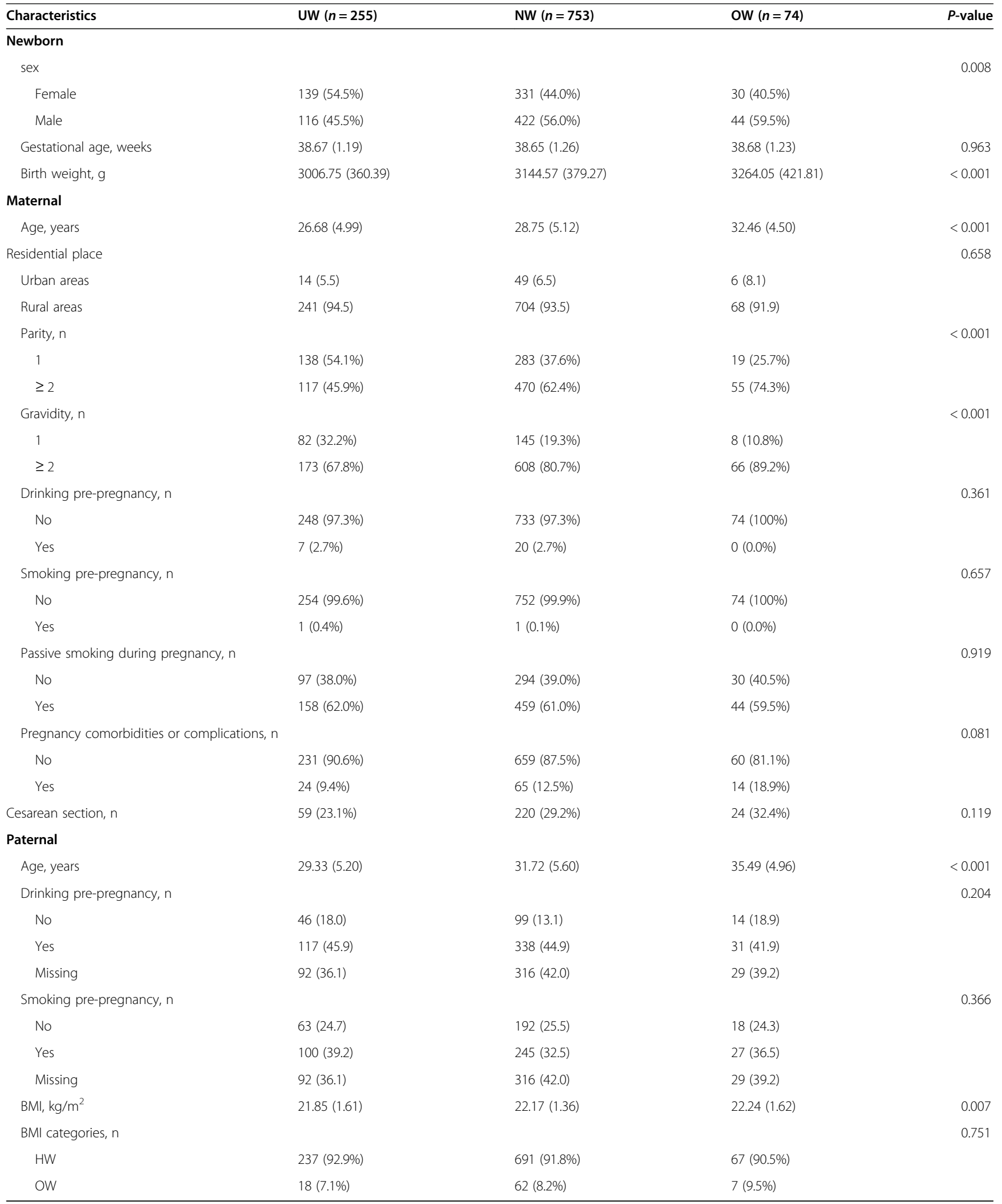

Values are presented as mean (SD), $\mathrm{n}(\%)$

Abbreviation: BMI Body mass index, UW Underweight, NW Normal weight, OW Overweight, HW Healthy weight (normal and underweight) 
Table 2 Categorized analysis between parental pre-pregnancy BMI and newborn $\mathrm{TL}$

\begin{tabular}{|c|c|c|c|c|c|c|}
\hline \multirow[t]{2}{*}{ All $(n=1082)$} & \multicolumn{2}{|l|}{ Unadjusted } & \multicolumn{2}{|l|}{ Model A } & \multicolumn{2}{|l|}{ Model B } \\
\hline & $\begin{array}{l}\text { Percentage change } \\
(95 \% \mathrm{Cl})\end{array}$ & $\overline{P \text {-value }}$ & $\begin{array}{l}\text { Percentage change } \\
(95 \% \mathrm{Cl})\end{array}$ & $P$-value & $\begin{array}{l}\text { Percentage change } \\
(95 \% \mathrm{Cl})\end{array}$ & $P$-value \\
\hline \multicolumn{7}{|l|}{ Maternal BMI } \\
\hline NW & Ref & & Ref & & Ref & \\
\hline UW & $-0.23(-4.50,4.23)$ & 0.937 & $0.23(-4.28,4.71)$ & 0.958 & $0.23(-4.28,4.95)$ & 0.929 \\
\hline OW & $-7.96(-14.49,-0.92)$ & 0.029 & $-8.17(-14.89,-0.92)$ & 0.026 & $-7.96(-14.49,-0.69)$ & 0.032 \\
\hline \multicolumn{7}{|l|}{ Paternal BMI } \\
\hline HW & Ref & & Ref & & Ref & \\
\hline OW & $0.69(-6.03,7.65)$ & 0.850 & $0.93(-5.59,8.14)$ & 0.785 & $0.93(-5.59,8.14)$ & 0.772 \\
\hline \multicolumn{7}{|c|}{ Parents' weight status combination } \\
\hline Both parents HW & Ref & & Ref & & Ref & \\
\hline OW father, HW mother & $0.46(-6.24,7.89)$ & 0.892 & $0.69(-6.24,7.89)$ & 0.869 & $0.69(-6.24,8.14)$ & 0.866 \\
\hline OW mother, HW father & $-8.17(-14.89,-0.92)$ & 0.030 & $-8.59(-15.67,-1.14)$ & 0.024 & $-8.38(-15.47,-0.92)$ & 0.028 \\
\hline Both parents OW & $-4.50(-23.97,20.23)$ & 0.698 & $-3.39(-23.26,21.62)$ & 0.768 & $-2.50(-22.55,22.74)$ & 0.830 \\
\hline
\end{tabular}

who were of normal weight before pregnancy. Further analysis of the combined effects of parental weight status on newborn TL showed that TL was significantly shortened among newborns whose mothers were overweight and fathers were of healthy weight when compared with those whose mothers and fathers were both of normal weight. Subgroup analysis indicated that these effects were more pronounced among male newborns and those whose paternal age $<31$ years or maternal age $\geq 28$ years.

Overweight and obesity leads to a higher ratio of systemic inflammation and reactive oxygen species (ROS) in adults $[25,26]$. Increasing levels of oxidative stress will lead to breakage of DNA and accelerated shortening of telomeres [27, 28]. Parental obesity has been linked to a range of adverse effects on newborn health outcomes. Higher maternal BMI is accompanied with a higher inflammatory and oxidative stress intrauterine environment for the developing fetus [29]. The changed intrauterine environment will lead to an adverse impact on telomere biology during the utero life and affect fetal programming [30]. The results of mothers in our study were similar to a recent study conducted by Dries $\mathrm{S}$ et al. [17]. However, they found cord blood TL were not significantly lower in overweight mothers compared to normal weight mothers, even in the unadjusted model. That might be explained by ethnicity-specific differences. Asians have a higher percentage of body fat compared to Caucasians with the same BMI [31].

We did not observe any significant association between paternal pre-pregnancy BMI and newborn TL, though most studies had concluded that male obesity had an inverse association with the quality of sperm [32-34] and the health outcomes of the next generation $[35,36]$. The effect of males being overweight does not appear to be great [35, $37,38]$, and it implied that the effect of maternal prepregnancy BMI on newborn TL was dominant. The phenomenon of parental BMI on newborn TL might be explained by the greater influence of mothers through the whole course of pregnancy. On the other hand, some studies reported that paternal effects on the next generation emerged later $[4,36]$. There were no obese fathers in our current study, therefore, it was understandable to have such a result between paternal BMI and newborn TL.

Stratified analysis showed that the effect of higher maternal pre-pregnancy BMI on male newborn TL was stronger than that of female newborns, Reyes et al. reported that the level of estrogen [39] among female fetuses is higher than male fetuses. Higher level of estrogen leads to higher antioxidant enzymes level by up-regulating superoxide dismutase and glutathione peroxidase gene expression [40]. Therefore, male fetuses might be more susceptible to oxidative stress caused by higher maternal pre-pregnancy BMI. The stratified analysis also indicated that the inverse association between maternal overweight and newborn TL was more pronounced among mothers $\geq 28$ years or fathers $<31$ years. Previous studies reported that newborn TL tended to be longer with increased paternal age [6]. Our current results implied that the positive effects of increased paternal age at delivery and the negative effects of maternal higher BMI before pregnancy on newborn TL might be additive. It was reported that there was an increased risk 
Table 3 Associations between parental pre-pregnancy BMI and newborn TL, stratified by newborn sex

\begin{tabular}{|c|c|c|c|c|c|c|}
\hline \multirow[t]{2}{*}{ Subgroup } & \multicolumn{2}{|l|}{ Unadjusted } & \multicolumn{2}{|l|}{ Model A } & \multicolumn{2}{|l|}{ Model B } \\
\hline & $\begin{array}{l}\text { Percentage change } \\
(95 \% \mathrm{CI})\end{array}$ & $P$-value & $\begin{array}{l}\text { Percentage change } \\
(95 \% \mathrm{Cl})\end{array}$ & $P$-value & $\begin{array}{l}\text { Percentage change } \\
(95 \% \mathrm{Cl})\end{array}$ & $P$-value \\
\hline \multicolumn{7}{|l|}{ Male $(n=582)$} \\
\hline \multicolumn{7}{|l|}{ Maternal BMI } \\
\hline NW & Ref & & Ref & & Ref & \\
\hline UW & $0.69(-5.38,7.15)$ & 0.839 & $0.23(-6.03,6.91)$ & 0.934 & $0.46(-5.81,7.15)$ & 0.905 \\
\hline OW & $-9.84(-17.96,-0.92)$ & 0.033 & $-9.22(-17.59,0.00)$ & 0.048 & $-9.01(-17.40,0.23)$ & 0.054 \\
\hline \multicolumn{7}{|l|}{ Paternal BMI } \\
\hline HW & Ref & & Ref & & Ref & \\
\hline OW & $2.33(-7.32,12.72)$ & 0.655 & $2.57(-7.10,12.98)$ & 0.616 & $2.09(-7.53,12.72)$ & 0.686 \\
\hline \multicolumn{7}{|c|}{ Parents' weight status combination } \\
\hline Both parents HW & Ref & & Ref & & Ref & \\
\hline OW father, HW mother & $2.80(-7.10,13.76)$ & 0.588 & $3.04(-6.89,14.02)$ & 0.568 & $2.33(-7.74,13.24)$ & 0.670 \\
\hline OW mother, HW father & $-9.43(-17.78,-0.23)$ & 0.047 & $-8.80(-17.40,0.69)$ & 0.071 & $-8.80(-17.59,0.69)$ & 0.068 \\
\hline Both parents OW & $-14.10(-39.19,21.34)$ & 0.388 & $-14.10(-39.19,21.34)$ & 0.388 & $-10.05(-36.61,27.64)$ & 0.550 \\
\hline \multicolumn{7}{|l|}{ Female $(n=500)$} \\
\hline \multicolumn{7}{|l|}{ Maternal BMI } \\
\hline NW & Ref & & Ref & & Ref & \\
\hline UW & $-0.23(-6.24,6.17)$ & 0.915 & $0.00(-6.03,6.66)$ & 0.972 & $0.46(-5.81,7.15)$ & 0.899 \\
\hline OW & $-5.16(-15.67,6.66)$ & 0.366 & $-6.67(-17.21,5.44)$ & 0.267 & $-6.46(-17.01,5.68)$ & 0.281 \\
\hline \multicolumn{7}{|l|}{ Paternal BMI } \\
\hline HW & Ref & & Ref & & Ref & \\
\hline OW & $-0.46(-9.43,9.65)$ & 0.932 & $-0.23(-9.43,9.90)$ & 0.965 & $0.23(-9.01,10.15)$ & 0.972 \\
\hline \multicolumn{7}{|c|}{ Parents' weight status combination } \\
\hline Both parents HW & Ref & & Ref & & Ref & \\
\hline OW father, HW mother & $-1.14(-10.67,9.14)$ & 0.804 & $-1.37(-10.67,9.14)$ & 0.803 & $-0.92(-10.26,9.65)$ & 0.867 \\
\hline OW mother, HW father & $-6.67(-17.59,5.68)$ & 0.280 & $-8.38(-19.46,4.23)$ & 0.179 & $-8.38(-19.46,4.23)$ & 0.187 \\
\hline Both parents OW & $3.99(-23.62,41.91)$ & 0.802 & $4.71(-23.26,43.22)$ & 0.767 & $4.95(-23.26,43.55)$ & 0.759 \\
\hline
\end{tabular}

Abbreviation: BMI Body mass index, TL Telomere length, UW Underweight, NW Normal weight, HW Normal and underweight, OW Overweight Models' adjustments were according to Table 2

of adverse perinatal outcomes with higher maternal age at delivery [41, 42]. Therefore, it was understandable that higher maternal age at delivery might increase the effect of maternal pre-pregnancy overweight on newborn TL. Besides, TL is shortened during each cell division, and it means that older fathers tend to have shorter TL generally. Longitudinal studies showed that an annual loss between 32.2 and $45.5 \mathrm{bp}$ is estimated in adult leukocytes [43], but, Wright et al. ever reported that germ line cells didn't show telomere shortening [44]. Therefore, the effect of parental age at delivery on newborn TL is still a controversial topic and further research is needed to determine the relationship between newborn $\mathrm{TL}$ and parental age at delivery. In the sensitivity analyses, our associations remained unchanged after adjusting for different covariates and potential cofounders and persisted after excluding major confounders, further suggesting an independent association between maternal overweight and newborn TL.

To our knowledge, our study was the first to investigate the association between parental pre-pregnancy BMI and newborn TL in Asia and was based on a relatively large sample size. The cohort is composed of citizens originally from Guangxi province and there was an advantage to analyzing homogeneous populations. In addition, the participants from 6 different counties gave our study a certain generalization for other populations. The very low number of smoking women was also a strength of our study, which enabled us to analyze the data without this confounding effects. However, our research had several limitations should be noted. First, parental weight and height were selfreported, which might lead to recall bias. Second, we did not adjust for some confounding factors, such as parental education, maternal prenatal folate concentration and 
Table 4 Associations between parental pre-pregnancy BMI and newborn TL, stratified by paternal age at delivery

\begin{tabular}{|c|c|c|c|c|}
\hline \multirow[t]{3}{*}{ Subgroup } & \multicolumn{4}{|l|}{ Paternal age at delivery (years) } \\
\hline & \multicolumn{2}{|l|}{$<31(n=496)$} & \multicolumn{2}{|l|}{$\geq 31(n=586)$} \\
\hline & Percentage change $(95 \% \mathrm{Cl})$ & $P$-value & Percentage change $(95 \% \mathrm{Cl})$ & $P$-value \\
\hline \multicolumn{5}{|l|}{ Maternal pre-pregnancy BMI } \\
\hline NW & Ref & & Ref & \\
\hline UW & $3.04(-3.17,9.40)$ & 0.341 & $-3.62(-10.05,3.28)$ & 0.292 \\
\hline OW & $-18.53(-33.17,-0.92)$ & 0.041 & $-6.46(-13.70,1.62)$ & 0.119 \\
\hline \multicolumn{5}{|l|}{ Paternal pre-pregnancy BMI } \\
\hline$H W$ & Ref & & Ref & \\
\hline OW & $-4.72(-13.90,5.20)$ & 0.337 & $6.66(-2.95,17.22)$ & 0.184 \\
\hline \multicolumn{5}{|c|}{ Parents' weight status combination* } \\
\hline Both parents HW & Ref & & Ref & \\
\hline OW father, HW mother & $-3.84(-13.30,6.66)$ & 0.451 & $5.44(-4.50,16.41)$ & 0.302 \\
\hline OW mother, HW father & $-19.83(-36.61,1.39)$ & 0.064 & $-6.24(-13.90,1.86)$ & 0.129 \\
\hline
\end{tabular}

Abbreviation: BMI, body mass index; TL, telomere length; UW, underweight; NW, normal weight; HW, normal and underweight; OW, overweight Models' adjustments were according to model B in Table 2

*Both parents OW was excluded for a small number $7(0.6 \%)$

enough paternal environmental lifestyle factors before pregnancy. These factors were reported to be associated with newborn TL or birth outcomes [45-48]. Third, although BMI is considered as a good measure of assessing overweight and obesity in adults, waist circumference, hip circumference, total body fat, and visceral adipose tissue volume [49] are also recommended to assess overweight and obesity. Fourth, the number of overweight participants in our study was relatively small, however, the socioeconomic status of Guangxi province [18] and the evidence from previous study [50] showed that the proportion of overweight participants in our study was understandable.
Lastly, previous studies showed that leukocyte TL was inversely associated with BMI in adulthood [51], and there was a strong correlation between newborn TL in cord blood and both parental TL [17]. Therefore, the association between pre-pregnancy maternal BMI and newborn TL might be mediated by parental TL. Further precise research is needed to explore the relationship between parental prepregnancy BMI and newborn TL.

\section{Conclusion}

In conclusion, maternal overweight, not paternal overweight before pregnancy may shorten newborn telomere

Table 5 Associations between parental pre-pregnancy BMI and newborn TL, stratified by maternal age at delivery

\begin{tabular}{|c|c|c|c|c|}
\hline \multirow[t]{3}{*}{ Subgroup } & \multicolumn{4}{|l|}{ Maternal age at delivery (years) } \\
\hline & \multicolumn{2}{|l|}{$<28(n=978)$} & \multicolumn{2}{|l|}{$\geq 28(n=104)$} \\
\hline & Percentage change $(95 \% \mathrm{Cl})$ & $P$-value & Percentage change $(95 \% \mathrm{Cl})$ & $P$-value \\
\hline \multicolumn{5}{|l|}{ Maternal pre-pregnancy BMI } \\
\hline NW & Ref & & Ref & \\
\hline UW & $-1.37(-7.10,4.71)$ & 0.647 & $1.16(-5.59,8.39)$ & 0.725 \\
\hline OW & $-3.17(-20.93,18.58)$ & 0.756 & $-8.38(-15.67,-0.46)$ & 0.038 \\
\hline \multicolumn{5}{|l|}{ Paternal pre-pregnancy BMI } \\
\hline$H W$ & Ref & & Ref & \\
\hline OW & $-1.37(-11.08,9.40)$ & 0.798 & $3.75(-5.38,13.76)$ & 0.434 \\
\hline \multicolumn{5}{|c|}{ Parents' weight status combination* } \\
\hline Both parents HW & Ref & & Ref & \\
\hline OW father, HW mother & $-0.23(-10.46,11.17)$ & 0.966 & $2.09(-7.10,12.20)$ & 0.675 \\
\hline OW mother, HW father & $2.33(-21.84,33.97)$ & 0.866 & $-9.22(-16.63,-1.37)$ & 0.023 \\
\hline
\end{tabular}

Abbreviation: BMI Body mass index, TL Telomere length, UW Underweight, NW Normal weight, HW Normal and underweight, OW Overweight Models' adjustments were according to model B in Table 2

*Both parents OW was excluded for a small number $7(0.6 \%)$ 
Table 6 Sensitivity analyses

\section{Maternal BMI}

Model B

NW

UW

OW

Excluding drinking before pregnancy

NW

UW

OW

Excluding passive smoking during pregnancy

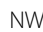

UW

OW

Excluding pregnancy comorbidities or complications

NW

UW

OW

Excluding preterm birth and low birth weight

NW

UW

OW

Excluding women from urban areas

NW

UW

OW

Paternal BMI

Model B

HW

OW

Excluding drinking before pregnancy

HW

OW

Excluding passive smoking during pregnancy

HW

OW

Excluding pregnancy comorbidities or complications

HW

OW

Excluding preterm birth and low birth weight

HW

OW

Excluding women from urban areas

HW

ow

Parents' weight status combination*

Model B

Both parents HW

OW father, HW mother
928

995

972

83

396

25

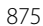

75

Percentage change $(95 \% \mathrm{Cl})$

$P$-value

Ref

$0.23(-4.28,4.95)$

0.929

$-7.96(-14.69,-0.69)$

0.032

Ref

$0.93(-3.62,5.68)$

0.678

$-7.74(-14.49,-0.69)$

0.034

Ref

$-3.84(-10.67,3.28)$

0.285

$-14.30(-23.62,-3.62)$

0.010

Ref

$0.00(-4.72,4.71)$

0.966

$-10.05(-17.21,-2.28)$

0.013

Ref

$0.46(-4.06,5.20)$

0.836

$-7.96(-14.69,-0.69)$

0.033

Ref

0.69(-3.84,5.44)

0.793

$-10.05(-16.82,-2.95)$

0.007

Ref

$0.93(-5.59,8.14)$

0.772

Ref

$-0.23(-6.89,6.91)$

0.960

Ref

$-4.50(-15.67,8.14)$

Ref

0.93(-6.24,8.64)

0.793

Ref

$1.39(-5.38,8.89)$

0.683

Ref

2.57(-4.28,9.90)

0.479

Ref

$0.69(-6.24,8.14)$
0.866 
Table 6 Sensitivity analyses (Continued)

\begin{tabular}{|c|c|c|c|}
\hline & $\mathrm{N}$ & Percentage change $(95 \% \mathrm{Cl})$ & $P$-value \\
\hline OW mother, HW father & 67 & $-8.38(-15.47,-0.92)$ & 0.028 \\
\hline \multicolumn{4}{|c|}{ Excluding drinking before pregnancy } \\
\hline Both parents HW & 905 & Ref & \\
\hline OW father, HW mother & 76 & $-0.69(-7.53,6.91)$ & 0.860 \\
\hline OW mother, HW father & 67 & $-8.59(-15.47,-1.14)$ & 0.026 \\
\hline \multicolumn{4}{|c|}{ Excluding passive smoking during pregnancy } \\
\hline Both parents HW & 368 & Ref & \\
\hline OW father, HW mother & 23 & $-3.62(-15.28,9.65)$ & 0.582 \\
\hline OW mother, HW father & 28 & $-13.30(-23.09,-2.28)$ & 0.021 \\
\hline \multicolumn{4}{|c|}{ Excluding pregnancy comorbidities or complications } \\
\hline Both parents HW & 820 & Ref & \\
\hline OW father, HW mother & 70 & $1.16(-6.24,9.14)$ & 0.784 \\
\hline OW mother, HW father & 55 & $-10.05(-17.40,-1.83)$ & 0.018 \\
\hline \multicolumn{4}{|c|}{ Excluding preterm birth and low birth weight } \\
\hline Both parents HW & 865 & Ref & \\
\hline OW father, HW mother & 75 & $1.16(-6.03,8.64)$ & 0.774 \\
\hline OW mother, HW father & 65 & $-8.59(-15.67,-0.92)$ & 0.027 \\
\hline \multicolumn{4}{|c|}{ Excluding women from urban areas } \\
\hline Both parents HW & 871 & Ref & \\
\hline OW father, HW mother & 74 & $2.09(-4.94,9.65)$ & 0.575 \\
\hline OW mother, HW father & 61 & $-10.87(-17.78,-3.39)$ & 0.005 \\
\hline
\end{tabular}

Abbreviation: BMI Body mass index, TL Telomere length, UW Underweight, NW Normal weight, HW Healthy weight (normal and underweight), OW Overweight Models' adjustments were according to model B in Table 2

Preterm birth was defined as a newborn with gestational age $<37$ weeks, low birth weight was defined as a newborn with birth weight $<2500 \mathrm{~g}$

*Both parents OW was excluded for a small number $7(0.6 \%)$

length. The trend of rapid economic growth and urbanization has a great influence on the Chinese population, and this includes the adoption of a sedentary lifestyle and the high availability of foods with high caloric content. Hence, our results comprise of an important public health finding. Weight control in reproductive women and effective healthy weight management before pregnancy may be of particular benefit for improving longevity and life quality of offspring.

\section{Abbreviations}

TL: Telomere length; BMI: Body mass index; T/S: Telomere copy number/ single-copy gene number; qPCR: Quantitative real-time polymerase chain reaction; Cl: Confidence interval; SD: Standard deviation; IQR: Interquartile range; ROS: Reactive oxygen species; UW: Underweight; NW: Normal weight; OW: Overweight; HW: Healthy weight (normal and underweight); AIC: Akaike information criterion

\section{Supplementary Information}

The online version contains supplementary material available at https://doi. org/10.1186/s12884-021-03757-x.

Additional file 1: Figure S1. Flowchart of the study parent-newborn pairs.

Additional file 2: Figure S2. Pearson correlation between parental prepregnancy BMI and newborn telomere length. (Relative average telomere lengths were expressed as the ratio of telomere copy number to singlecopy gene number (T/S ratio). a Maternal BMI. b Paternal BMI).
Additional file 3: Figure S3. Restricted cubic spline analysis of the correlation between parental BMl and newborn telomere length. (Relative average telomere lengths were expressed as the ratio of telomere copy number to single-copy gene number (T/S ratio). c. Maternal BMI (knots= 3). d. Paternal BMI (knots=6).

Additional file 4: Table S1. Categorized analysis between parental prepregnancy BMI and newborn TL $(n=645)$.

Additional file 5: Table S2. Interaction between parental prepregnancy $\mathrm{BMI}$ and newborn sex or parental age at delivery.

\section{Acknowledgements}

We gratefully thank all the study participants in this study and the staffs for their contributions in this study. We gratefully acknowledge all the following participant institutions: Tiandong People's Hospital, Tiandong Maternity and Child Health Care Hospital, Jingxi People's Hospital, Jingxi Maternity and Child Health Care Hospital, Pingguo People's Hospital, Pingguo Maternity and Child Health Care Hospital, Debao People's Hospital, Debao Maternity and Child Health Care Hospital, Longan People's Hospital, Wuming People's Hospital, Wuming Maternity and Child Health Care Hospital, and Guangxi Medical University Clinical Epidemiology Research Center for Multifactorial Diseases.

\section{Authors' contributions}

XQQ: Project administration, Resources, Data Curation, Writing-Review \& Editing, Supervision, Funding acquisition; DPH: Conceptualization, Methodology, Resources, Writing-Review \& Editing, Supervision; SL: Conceptualization, Methodology, Data Curation, Writing Review \& Editing, Supervision; BCW: Methodology, Data interpretation and statistical analysis, Investigation, Writing the manuscript, Visualization; YTS performed the DNA extraction and measured cord blood telomere under supervision of XQQ, DPH; JL, PT, MLM, BHL and HSH: investigation, Data Curation; SL and HJJT critically revised the 
manuscript for important intellectual content. All authors critically reviewed and approved the manuscript.

\section{Funding}

This work was supported by the Natural Science Foundation of China (81460517) and (81860587), and Guangxi Key Research Program (AB17195012). The funders had no role in the study design, data collection, analysis, or interpretation of the data, writing the report or the decision to submit the paper for publication.

\section{Availability of data and materials}

The datasets for the current study are available from the corresponding author on reasonable request.

\section{Declarations}

\section{Ethics approval and consent to participate}

This study was approved by the ethical committee of Guangxi Medical University (No.20140305-001). Individual written informed consent was obtained from all participants at enrollment.

\section{Consent for publication}

Not applicable.

\section{Competing interests}

The authors declare that they have no competing interests.

\section{Author details}

'Department of Epidemiology and Health Statistics, School of Public Health, Guangxi Medical University, No. 22 Shuangyong Road, Nanning 530021, Guangxi, China. ${ }^{2}$ Department of Student Work, The First Clinical Medical College of Guangxi Medical University, Nanning 530021, Guangxi, China. ${ }^{3}$ Yong Loo Lin School of Medicine, National University of Singapore, 10 Medical Dr, Singapore 117597, Singapore. ${ }^{4}$ Department of Sanitary Chemistry, School of Public Health, Guangxi Medical University, No. 22 Shuangyong Road, Nanning 530021, Guangxi, China. ${ }^{5}$ Department of Maternal, Child and Adolescent Health, School of Public Health, Guangxi Medical University, No. 22 Shuangyong Road, Nanning 530021, Guangxi, China.

\section{Received: 4 October 2020 Accepted: 24 March 2021}

Published online: 09 April 2021

\section{References}

1. Yang S, Zhou A, Xiong C, Yang R, Bassig BA, Hu R, et al. Parental body mass index, gestational weight gain, and risk of Macrosomia: a population-based case-control study in China. Paediatr Perinat Epidemiol. 2015;29(5):462-71. https://doi.org/10.1111/ppe.12213.

2. Cadenas-Sanchez C, Henriksson P, Henriksson H, Nystrom CD, Pomeroy J, Ruiz JR, et al. Parental body mass index and its association with body composition, physical fitness and lifestyle factors in their 4-year-old children: results from the MINISTOP trial. Eur J Clin Nutr. 2017;71(10):1200-5. https:// doi.org/10.1038/ejcn.2017.62

3. Magnus MC, Olsen SF, Granstrom C, Lund-Blix NA, Svensson J, Johannesen $J$, et al. Paternal and maternal obesity but not gestational weight gain is associated with type 1 diabetes. Int J Epidemiol. 2018;47(2):417-26. https:// doi.org/10.1093/ije/dyx266.

4. Jansen MAC, Dalmeijer GW, Saldi SR, Grobbee DE, Baharuddin M, Uiterwaal CS, et al. Pre-pregnancy parental BMI and offspring blood pressure in infancy. Eur J Prev Cardiol. 2019;26(15):1581-90. https://doi.org/10.1177/204 7487319858157

5. Blackburn EH, Epel ES, Lin J. Human telomere biology: a contributory and interactive factor in aging, disease risks, and protection. Science. 2015; 350(6265):1193-8. https://doi.org/10.1126/science.aab3389.

6. Factor-Litvak P, Susser E, Kezios K, McKeague I, Kark JD, Hoffman M, et al. Leukocyte Telomere Length in Newborns: Implications for the Role of Telomeres in Human Disease. Pediatrics. 2016;137:4.

7. Heidinger BJ, Blount JD, Boner W, Griffiths K, Metcalfe NB, Monaghan P. Telomere length in early life predicts lifespan. Proc Natl Acad Sci U S A. 2012;109(5):1743-8. https://doi.org/10.1073/pnas.1113306109.

8. Eastwood JR, Hall ML, Teunissen N, Kingma SA, Hidalgo Aranzamendi N, Fan $M$, et al. Early-life telomere length predicts lifespan and lifetime reproductive success in a wild bird. Mol Ecol. 2019;28(5):1127-37. https:// doi.org/10.1111/mec.15002

9. Shen Q, Zhao X, Yu L, Zhang Z, Zhou D, Kan M, et al. Association of leukocyte telomere length with type 2 diabetes in mainland Chinese populations. J Clin Endocrinol Metab. 2012;97(4):1371-4. https://doi.org/1 0.1210/jc.2011-1562.

10. Brouilette SW, Moore JS, MCMahon AD, Thompson JR, Ford I, Shepherd J, et al. West of Scotland coronary prevention study G: telomere length, risk of coronary heart disease, and statin treatment in the west of Scotland primary prevention study: a nested case-control study. Lancet. 2007;369(9556):10714. https://doi.org/10.1016/S0140-6736(07)60071-3.

11. Wang Z, Zhang Z, Guo Y, Shui H, Liu G, Jin T, et al. Shorter telomere length is associated with increased breast Cancer risk in a Chinese Han population: a case-control analysis. J Breast Cancer. 2018;21(4):391-8. https://doi.org/10.4 048/jbc.2018.21.e52.

12. Hjelmborg JB, Dalgard C, Moller S, Steenstrup T, Kimura M, Christensen K, et al. The heritability of leucocyte telomere length dynamics. J Med Genet. 2015;52(5):297-302. https://doi.org/10.1136/jmedgenet-2014-102736.

13. Entringer S, Epel ES, Lin J, Buss C, Shahbaba B, Blackburn EH, et al. Maternal psychosocial stress during pregnancy is associated with newborn leukocyte telomere length. Am J Obstet Gynecol. 2013;208:2.

14. Wang LL, Song LL, Liu BQ, Zhang LN, Wu MY, Xia W, et al. Earlier maternal menarche is associated with shorter newborn telomere length. Eur J Pediatr. 2020;179(10):1507-13. https://doi.org/10.1007/s00431-020-03621-8.

15. Liu B, Song L, Zhang L, Wu M, Wang L, Cao Z, et al. Prenatal second-hand smoke exposure and newborn telomere length. Pediatr Res. 2020;87(6): 1081-5. https://doi.org/10.1038/s41390-019-0594-2

16. Zhang L, Song L, Liu B, Wu M, Wang L, Zhang B, et al. Prenatal cadmium exposure is associated with shorter leukocyte telomere length in Chinese newborns. BMC Med. 2019:17(1):27. https://doi.org/10.1186/s12916-019-1262-4.

17. Martens DS, Plusquin M, Gyselaers W, De Vivo I, Nawrot TS. Maternal prepregnancy body mass index and newborn telomere length. BMC Med. 2016;14(1):148. https://doi.org/10.1186/s12916-016-0689-0.

18. Zhou Z, Tang Q, Chen X, Yu T, Huang W, Liang F. The association between the socioeconomic status and systemic comorbidities in patients with oral cancers: a retrospective study in Guangxi Province. Clin Oral Investig. 2020; 25(3): 1085.

19. Liang J, Liu S, Liu T, Yang C, Wu Y, Jennifer Tan HJ, et al. Association of prenatal exposure to bisphenols and birth size in Zhuang ethnic newborns. Chemosphere. 2020;252:126422. https://doi.org/10.1016/j.chemosphere.202 0.126422

20. Bei-Fan Z, Working CMAG. Predictive values of body mass index and waist circumference for risk factors of certain related diseases in Chinese adults: study on optimal cut-off points of body mass index and waist circumference in Chinese adults. Asia Pac J Clin Nutr. 2002:11:5685-93. https://doi.org/10.1046/j.1440-6047.11.s8.9.x.

21. Cawthon RM. Telomere measurement by quantitative PCR. Nucleic Acids Res. 2002;30(10):e47-447. https://doi.org/10.1093/nar/30.10.e47.

22. Rao $X$, Huang $X$, Zhou Z, Lin X. An improvement of the $2 \wedge(-$ delta delta $C T)$ method for quantitative real-time polymerase chain reaction data analysis. Biostat Bioinforma Biomath. 2013:3(3):71-85.

23. Saenen ND, Martens DS, Neven KY, Alfano R, Bove H, Janssen BG, et al. Air pollution-induced placental alterations: an interplay of oxidative stress, epigenetics, and the aging phenotype? Clin Epigenetics. 2019;11(1):124. https://doi.org/10.1186/s13148-019-0688-z.

24. Martens DS, Cox B, Janssen BG, Clemente DBP, Gasparrini A, Vanpoucke C, et al. Prenatal air pollution and Newborns' predisposition to accelerated biological aging. JAMA Pediatr. 2017;171(12):1160-7. https://doi.org/10.1001/ jamapediatrics.2017.3024

25. Furukawa S, Fujita T, Shimabukuro M, Iwaki M, Yamada Y, Nakajima Y, et al. Increased oxidative stress in obesity and its impact on metabolic syndrome. I Clin Invest. 2004;114(12):1752-61. https://doi.org/10.1172/JCI21625.

26. Ahima RS. Connecting obesity, aging and diabetes. Nat Med. 2009;15(9): 996-7. https://doi.org/10.1038/nm0909-996.

27. von Zglinicki T. Oxidative stress shortens telomeres. Trends Biochem Sci. 2002;27(7):339-44. https://doi.org/10.1016/S0968-0004(02)02110-2.

28. Kawanishi S, Oikawa S. Mechanism of telomere shortening by oxidative stress. Ann N Y Acad Sci. 2004;1019(1):278-84. https://doi.org/10.1196/annals.1297.047.

29. Malti N, Merzouk H, Merzouk SA, Loukidi B, Karaouzene N, Malti A, et al. Oxidative stress and maternal obesity: feto-placental unit interaction. Placenta. 2014;35(6):411-6. https://doi.org/10.1016/j.placenta.2014.03.010. 
30. Myatt L. Placental adaptive responses and fetal programming. J PhysiolLondon. 2006;572(1):25-30. https://doi.org/10.1113/jphysiol.2006.104968.

31. Barba C, Cavalli-Sforza T, Cutter J, Darnton-Hill I, Deurenberg P, Deurenberg-Yap $M$, et al. Appropriate body-mass index for Asian populations and its implications for policy and intervention strategies. Lancet. 2004;363(9403):157-63.

32. Fariello RM, Pariz JR, Spaine DM, Cedenho AP, Bertolla RP, Fraietta R. Association between obesity and alteration of sperm DNA integrity and mitochondrial activity. BJU Int. 2012;110(6):863-7. https://doi.org/10.1111/ j.1464-410X.2011.10813.x

33. Campbell JM, Lane M, Owens JA, Bakos HW. Paternal obesity negatively affects male fertility and assisted reproduction outcomes: a systematic review and meta-analysis. Reprod BioMed Online. 2015;31(5):593-604. https://doi.org/10.1016/j.rbmo.2015.07.012.

34. Leisegang K, Bouic PJD, Menkveld R, Henkel RR. Obesity is associated with increased seminal insulin and leptin alongside reduced fertility parameters in a controlled male cohort. Reprod Biol Endocrinol. 2014;12(1):34. https:// doi.org/10.1186/1477-7827-12-34.

35. Potabattula R, Dittrich M, Schorsch M, Hahn T, Haaf T, El Hajj N. Male obesity effects on sperm and next-generation cord blood DNA methylation. PLoS One. 2019;14(6):e0218615. https://doi.org/10.1371/ journal.pone.0218615.

36. Linabery AM, Nahhas RW, Johnson W, Choh AC, Towne B, Odegaard AO, et al. Stronger influence of maternal than paternal obesity on infant and early childhood body mass index: the Fels longitudinal study. Pediatr Obes. 2013;8(3):159-69. https://doi.org/10.1111/j.2047-6310.2012.00100.x.

37. Mikkelsen SH, Hohwu L, Olsen J, Bech BH, Liew Z, Obel C. Parental body mass index and behavioral problems in their offspring: a Danish National Birth Cohort Study. Am J Epidemiol. 2017;186(5):593-602. https://doi.org/1 0.1093/aje/kwx063.

38. Soubry A, Murphy SK, Wang F, Huang Z, Vidal AC, Fuemmeler BF, et al. Newborns of obese parents have altered DNA methylation patterns at imprinted genes. Int J Obes. 2015;39(4):650-7. https://doi.org/10.1038/ijo.2 013.193.

39. Reyes Fl, Boroditsky RS, Winter JS, Faiman C. Studies on human sexual development. II. Fetal and maternal serum gonadotropin and sex steroid concentrations. J Clin Endocrinol Metab. 1974;38(4):612-7. https://doi.org/1 0.1210/jcem-38-4-612.

40. Vina J, Gambini J, Lopez-Grueso R, Abdelaziz KM, Jove M, Borras C. Females live longer than males: role of oxidative stress. Curr Pharm Design. 2011; 17(36):3959-65. https://doi.org/10.2174/138161211798764942.

41. Wu Y, Chen Y, Shen M, Guo Y, Wen SW, Lanes A, et al. Adverse maternal and neonatal outcomes among singleton pregnancies in women of very advanced maternal age: a retrospective cohort study. BMC Pregnancy Childbirth. 2019;19(1):3. https://doi.org/10.1186/s12 884-018-2147-9

42. Odame Anto E, Owiredu W, Sakyi SA, Turpin CA, Ephraim RKD, Fondjo LA et al. Adverse pregnancy outcomes and imbalance in angiogenic growth mediators and oxidative stress biomarkers is associated with advanced maternal age births: a prospective cohort study in Ghana. PLoS One. 2018; 13(7):e0200581. https://doi.org/10.1371/journal.pone.0200581.

43. Muezzinler A, Zaineddin AK, Brenner H. A systematic review of leukocyte telomere length and age in adults. Ageing Res Rev. 2013;12(2):509-19. https://doi.org/10.1016/j.arr.2013.01.003.

44. Wright WE, Piatyszek MA, Rainey WE, Byrd W, Shay JW. Telomerase activity in human germline and embryonic tissues and cells. Dev Genet. 1996;18(2): 173-9. https://doi.org/10.1002/(SICI)1520-6408(1996)18:2<173::AID-DVG10>3. $0 . \mathrm{CO} ; 2-3$.

45. Colaco S, Sakkas D. Paternal factors contributing to embryo quality. J Assist Reprod Genet. 2018;35(11):1953-68. https://doi.org/10.1007/s1081 5-018-1304-4.

46. Wojcicki JM, Olveda R, Heyman MB, Elwan D, Lin J, Blackburn E, et al. Cord blood telomere length in Latino infants: relation with maternal education and infant sex. J Perinatol. 2016;36(3):235-41. https://doi.org/1 0.1038/jp.2015.178.

47. Entringer S, Epel ES, Lin J, Blackburn EH, Buss C, Shahbaba B, et al. Maternal Folate concentration in early pregnancy and newborn telomere length. Ann Nutr Metab. 2015:66(4):202-8. https://doi.org/10.1159/000381925.

48. Agarwal A, Cho CL, Esteves SC. Should we evaluate and treat sperm DNA fragmentation? Curr Opin Obstet Gynecol. 2016;28(3):164-71. https://doi. org/10.1097/GCO.0000000000000271.
49. Lee M, Martin H, Firpo MA, Demerath EW. Inverse association between adiposity and telomere length: the Fels longitudinal study. Am J Hum Biol. 2011;23(1):100-6. https://doi.org/10.1002/ajhb.21109.

50. Li CM, Liu YJ, Zhang WY. Joint and independent associations of gestational weight gain and pre-pregnancy body mass index with outcomes of pregnancy in chinese women: a retrospective cohort study. PLoS One. 2015;10:8.

51. Muezzinler A, Zaineddin AK, Brenner H. Body mass index and leukocyte telomere length in adults: a systematic review and meta-analysis. Obes Rev. 2014;15(3):192-201. https://doi.org/10.1111/obr.12126.

\section{Publisher's Note}

Springer Nature remains neutral with regard to jurisdictional claims in published maps and institutional affiliations.

\section{Ready to submit your research? Choose BMC and benefit from:}

- fast, convenient online submission

- thorough peer review by experienced researchers in your field

- rapid publication on acceptance

- support for research data, including large and complex data types

- gold Open Access which fosters wider collaboration and increased citations

- maximum visibility for your research: over $100 \mathrm{M}$ website views per year

At $\mathrm{BMC}$, research is always in progress.

Learn more biomedcentral.com/submissions 